\title{
Analytical and Numerical Study on the Fast Refill of Compressed Natural Gas with Active Heat Removal
}

\author{
Guoyu Zhang ${ }^{1 *}$, Joshua Brinkerhoff ${ }^{1}, \mathrm{Ri} \mathrm{Li}^{1}$, Chris Forsberg ${ }^{2}$, Todd Sloan ${ }^{2}$ \\ ${ }^{1}$ The University of British Columbia, Okanagan Campus, Kelowna, Canada, V1V 1V7 \\ ${ }^{2}$ Agility Fuel Systems, Kelowna, Canada, V1Y 6H7
}

\begin{abstract}
Abbreviated title:
\end{abstract}




\begin{abstract}
Heavy-duty vehicles powered by compressed natural gas (CNG) store the fuel in large onboard cylinders. Fast fill of depleted CNG cylinders is a common refueling method because it achieves refueling time comparable to liquid fuels. However, under-filling of CNG cylinders occurs during fast fill due to the recompression work of CNG in the cylinder that heats the fuel during the fill. The heated fuel has a lower density at the rated pressure, and thus less mass of CNG can be stored than if it was at ambient temperature. To increase the mass of dispensed CNG during fast fill, an active heat removal method is proposed. In this study, analytical and numerical models of the filling process of CNG into a Type-III cylinder with and without active heat removal are developed. In the analytical study, mass and energy conservation equations are coupled with an ideal-gas equation of state and orifice flow equations to predict the heat generation rates during fast fill. The influence of heat removal via a cooling coil inserted into the cylinder during fill on the dispensed mass and fill time is quantified. The analytical study is compared to numerical simulations employing a two-dimensional axisymmetric computational fluid dynamics (CFD) model for unsteady, compressible turbulent flow in a TypeIII cylinder with and without active heat removal. Dynamic average temperature, pressure and mass curves as well as the local temperature distribution in the cylinder are obtained at different time instances during the fill. The effect of the location of the heat removal coils is also investigated. The results of the analytical/numerical study illustrate the benefit of heat removal from the cylinder as a means of improving fast-fill efficiency in natural gas fueled heavy-duty vehicles.
\end{abstract}

KEY WORDS: Compressed natural gas, fast filling, active heat removal, analytical and numerical study 


\section{INTRODUCTION}

For the past few years, natural gas has played a prominent role in energy discussions around the world [12]. One reason is the emergence of abundant supplies of natural gas following the development of unconventional extraction methods. For example, the development of shale gas in USA has increased its production from 456 billion scf per year to 9198 billion scf per year from 2000 to 2012 [3]. Another driver is the lower carbon emissions of natural gas relative to other fossil fuels, which has important implications for the transportation section that is responsible for $20 \%$ of the global carbon dioxide emissions [4]. Given the increasing energy demand and high greenhouse gas (GHG) emissions associated with conventional fossil fuels, Yeh [5] concluded that shifting the transportation sector to natural gas can significantly reduce GHG emissions.

Due to the low volumetric energy density of natural gas relative to liquid fuels, transportation systems typically store fuel either as a low-temperature liquefied natural gas (LNG) or a high-pressure compressed natural gas (CNG), of which CNG currently has higher market share [6]. There are two kinds of fill methods for CNG: time fill and fast fill. Time fill dispensing is slower, but allows for the compression to occur at closer to isothermal conditions, which leads to fuller tanks. For most public stations and for fleets requiring quick refuelling, fast fill is required. As found by Kountz [7,8], underfilling of the cylinder is unavoidable during fast fill because of the heat generated during re-compression of CNG in the cylinder. During the fill process, high pressure CNG flows through the dispenser throttling device and enters the cylinder with reduced temperature because of the Joule-Thomson effect. The filled natural gas is then gradually heated via recompression by the continuously incoming gas, stopping when the internal pressure reaches the allowed cylinder pressure. Due to the recompression work, the temperature at the end of fast fill is typically about $50^{\circ} \mathrm{F}$ above the ambient temperature [7]. As a result, the charged mass of CNG is less than the rated storage capacity of the cylinder, and as the filled gas cools to ambient temperature, its pressure will decrease 
below the rated pressure. The fill efficiency — defined as the ratio of the actual filled mass to the capacity at the rated pressure and ambient temperature - is used to evaluate CNG filling. Fast fill of CNG cylinders at $20^{\circ} \mathrm{C}$ ambient temperature typically achieves a fill efficiency of $80 \%$ [8].

Fill efficiency of the fast fill process depends on several factors, including the CNG cylinder type and material, the CNG fill station pressure, and the transient heat transfer and gas transport inside the cylinder. Four types of CNG cylinders are commonly used for natural gas vehicles: Type-I cylinders are entirely metal. Type-II cylinders have a metal liner and hoop wrapped composite reinforcement. Type-III cylinders consist of a metal liner and full wrapped composite re-enforcement. Type-IV cylinders have a non-metallic liner and a fully wrapped composite reinforcement [9]. The different materials have varying thermalphysical properties, particularly thermal conductivity, density and specific heat, which affect the heat transfer from the gas to the surroundings during the fill process. Diggins [10] and Newhouse et al. [11] compared the fill efficiency of different cylinder types, and found that metal cylinders have higher fill efficiency than all-composite cylinders due to the better heat absorption and conduction of the metal wall.

Many studies have been conducted to investigate the transient thermal behaviour during fast fill $[7,8,11$, 13-16]. Kountz [7] and Farzaneh-Gord et al. [15] focused on mathematical theory and modelling of CNG fast fill. Shipley [13] experimentally measured the temperature rise of CNG with different ambient temperatures, and observed under-fill of test cylinders for all the fast fill tests. Farzaneh-Gord et al. [16] studied the effect of initial conditions on the fill efficiency of CNG cylinders by varying the initial pressure between 1 bar and 100 bar and initial temperature between $280 \mathrm{~K}$ and $320 \mathrm{~K}$. The same group [17] also found that the composition of natural gas affects the filling process and final in-cylinder conditions, where gas with lower methane percentage in its composition yields higher fill efficiencies. Some researchers have investigated the transient thermal behaviour during gas filling by numerical methods. Dicken and Merida [23] used computational fluid dynamics (CFD) to simulate the transient temperature distribution in the cylinder during filling of hydrogen cylinders. Nahavandi et al. also carried out CFD simulations of fast fill, 
comparing the temperature rise, pressure curves, and fill efficiency for natural gas [24] and hydrogen [25, 26].

There have been several approaches to address fill efficiency by focusing only on the fueling station side. Kountz et al. [18-21] proposed a temperature-compensated procedure that minimizes the heat of recompression by optimizing the CNG station and reservoir pressures. However, Farzaneh-Gord and DeymiDashtebayaz [22] showed that this procedure requires proper fill equipment and control systems, limiting its practicality. Moreover, selecting either a buffer or cascade filling strategies does not make much different, as Deymi-Dashtebayaz [27] showed that while filling time of buffer systems is much less than cascade systems, the filled mass is approximately the same. Owing to the inability of these station-side approaches to improve fill efficiency, most fill procedures over-pressurize the cylinder to compensate; for a Type-IV cylinder rated at 3600 psi, over-pressurization may exceed $4100 \mathrm{psi}$, which certainly presents safety implications.

Very few of the above studies have investigated potential solutions to improve fill efficiency that act on the cylinder being filled. Because heat generation during fast fill is inevitable, concepts that can actively or passively remove the generated heat during the fill process are required to achieve the needed improvements in fill efficiency. The objective of the present study is to investigate the fast fill process of natural gas in Type-III cylinders with and without active heat removal in order to identify the effectiveness of heat removal for improving fill efficiency in heavy-duty vehicles. The active heat removal system involves placing cooling coils inside the cylinder through which a coolant is circulated to remove heat from the cylinder and eject it to the surroundings. The passive heat removal system involves pre-chilling thermal heat sinks in the cylinder.

The paper is structured as follows: in Sections 2 and 3, an analytical model and a two-dimensional axisymmetric CFD model incorporating real gas effects are respectively developed to predict the transient 
thermal-fluid behaviour of natural gas during the fill. In Section 4, the models are used to investigate the effects of heat removal rate and the location of the cooling coils on the fill efficiency. Local and average gas temperatures, pressure, and velocity distributions in the cylinder are presented at several instances during the fill to explain the physical mechanisms governing the heat removal effectiveness and the resulting fill efficiency.

\section{ANALYTICAL MODEL}

\subsection{Model System and Assumptions}

Figure 1 shows a schematic diagram of the system under consideration consisting of a Type- 3 cylinder with a volume of $V=23.4 \mathrm{~L}$ filled with natural gas. The natural gas composition in Kountz's study [7] $\left(\mathrm{CH}_{4}\right.$ 92.87\%; $\mathrm{C}_{2} \mathrm{H}_{6} 3.34 \% ; \mathrm{N}_{2} 2.07 \% ; \mathrm{CO}_{2} 0.78 \% ; \mathrm{C}_{3} \mathrm{H}_{8} 0.63 \%$; less than $0.1 \%$ of $i$-butane, $n$-butane, $i$-pentane, $n$-pentane, and $n$-hexane, by molar percentages), which is the mean U.S. natural gas composition, has been used in our model. The gas has an initial pressure of $P_{i}=2 \mathrm{MPa}$ and temperature of $T_{i}=300 \mathrm{~K}$. The gas source and the cylinder are connected by a tube with orifice diameter of $d=5 \mathrm{~mm}$ and length $l=98 \mathrm{~mm}$. At the inlet to the tube, a gas total pressure of $P_{S}=20.6 \mathrm{MPa}$ and temperature of $T_{S}=300 \mathrm{~K}$ are imposed so that the corresponding total enthalpy $h_{s}$ is fixed. The effect of actively removing the heat generated during the fill is incorporated into the model by assuming that the heat removal system consists of a coiled tube with circulating coolant inserted from the other end of the cylinder. By assuming a high heat transfer coefficient of the coolant flow and high thermal conductivity of the cooling tube, a constant temperature condition of $T_{c}=300 \mathrm{~K}$ can be assumed on the coil outer surface. The convective heat transfer coefficient between the gas and the tube wall, $h$, and area of the tube, $A_{c}$, are expected to play major roles in the active cooling.

The following assumptions are made in this model: 
1. The gas pressure and temperature are spatially uniform, i.e. the filling process can be viewed as quasisteady;

2. The natural gas flow into the cylinder can be considered as isenthalpic expansion through the orifice;

3. The temperature and pressure of the supply gas are constant;

4. Heat transfer between the cylinder outer surface and the ambient is negligible, as per Kountz's analysis [7].

5. When considering adding cooling coils, the $h A_{c}$ value is assumed to be constant during the fill.

\subsection{Model Development}

Applying conservation of energy to the system in Fig. 1 yields:

$$
\dot{m} h_{s}-h A_{c}\left(T_{g}-T_{c}\right)=\frac{d}{d t}\left(m_{g} u_{g}\right)
$$

where $\dot{m}$ is the mass flow rate, $T_{g}$ denotes the gas average temperature, and $m_{g}$ and $u_{g}$ are the total mass and the specific internal energy of the gas inside the cylinder. The term $h A_{c}$ equals to 0 when active heat removal is not considered. Because the cylinder only has one inlet and no outlets, conservation of mass is:

$$
\frac{d m_{g}}{d t}=\dot{m}
$$

The equation of state is given by: 


$$
p_{g} v_{g}=R z_{g} m_{g} T_{g}
$$

where $p_{g}, v_{g}$ and $z_{g}$ are the pressure, specific volume and compressibility factor of the gas, and $R$ denotes the gas constant.

Finally, the equations describing the orifice flow rate [7] are provided as:

$$
\dot{m}=C C_{d} A \frac{P_{s}}{\sqrt{T_{s}}} f\left(\frac{P_{g}}{P_{s}}\right)
$$

Here $C_{d}$ is the orifice discharge coefficient, and $A$ is the orifice cross-section area. The coefficient $C$ is given by:

$$
C=\sqrt{\frac{g k}{R\left(\frac{k+1}{2}\right)^{\frac{k+1}{k-1}}}}
$$

Here $g$ denotes the dimensionalizing factor, and $k$ denotes the ratio of specific heat of the gas.

The function $f$ in Eq. (4) depends on pressure ratio $\frac{P_{g}}{P_{s}}$ in comparison to a critical value, which is

$$
\left(\frac{P_{g}}{P_{s}}\right)_{\text {crit }}=\left(\frac{2}{k+1}\right)^{\frac{k}{k-1}}
$$

If $\frac{P_{g}}{P_{S}} \leq\left(\frac{P_{g}}{P_{s}}\right)_{c r i t}$

$$
f\left(\frac{P_{g}}{P_{S}}\right)=1
$$


If $\frac{P_{g}}{P_{s}}>\left(\frac{P_{g}}{P_{s}}\right)_{\text {crit }}$

$$
f\left(\frac{P_{g}}{P_{S}}\right)=\sqrt{\left(\frac{2}{k-1}\right)\left(\frac{k+1}{2}\right)^{\frac{k+1}{k-1}}}\left(\frac{P_{g}}{P_{S}}\right)^{\frac{1}{k}} \sqrt{1-\left(\frac{P_{g}}{P_{S}}\right)^{\frac{k-1}{k}}}
$$

Previous studies have shown that non-ideal gas properties of $\mathrm{CNG}$ affect the final in-cylinder conditions. For instance, Farzaneh-Gord and Branch [30] estimate a temperature rise during refuelling of about $40 \mathrm{~K}$ when using real gas properties and more than $80 \mathrm{~K}$ when using ideal gas properties, with a corresponding effect on the fill efficiency. Therefore, the ideal gas assumption is not valid for natural gas filling process. Real gas thermophysical properties (enthalpy, internal energy and compressibility factor) are obtained after providing the composition, temperature and pressure of CNG from the NIST database program STRAPP®. These thermophysical properties have been curve-fitted to yield functions of temperature and pressure. These functions together with the above governing equations yield a system of ordinary differential equations that is solved using a fourth-order Runge-Kutta method to obtain the transient solutions for the average gas temperature, pressure and the total mass inside the cylinder. The fill is considered to be completed at time $t$ when the average gas pressure $p_{g}(t)$ satisfies the following equation:

$$
\frac{p_{g}(t)-p_{i}}{p_{s}-p_{i}}=95 \%
$$

\subsection{Transient Solutions and the Effects of Adding Cooling Coil}

Figures 2-4 show the average gas pressure, temperature and mass without cooling and with a cooling coil that has a high value of $h A_{c}=280 \mathrm{~W} / \mathrm{K}$. Figure 2 shows that the fill process is completed when the average pressure reaches 19.6 $\mathrm{MPa}$, and the time required to complete the fill increases with active heat removal. 
Figure 3 shows that the average gas temperature at the end of the fill can be lowered significantly with active heat removal, and Fig. 4 shows the corresponding increase in the mass of filled CNG for the case with the largest heat removal rate. The effect of the heat removal rate is shown in Fig. 3 through dynamic temperature curves with multiple cooling scenarios $\left(h A_{c}=0,70,140,210\right.$ and $\left.280 \mathrm{~W} / \mathrm{K}\right)$. Overall, as the cooling effect becomes stronger, the mean gas temperature is lower at the same filling time. The temperature increases at the beginning due to the heat generated by compression work. Only the gas near the inlet is cooled by the Joule-Thomson effect, and because this portion is only a small fraction of the total mass of gas in the cylinder, there is no noticeable temperature dip in Fig. 3 early in the fill; this is also observed in the CFD results in the following section.

Several additional observations can be made from Fig. 4. The mass increases linearly in the first 20 seconds

because the pressure ratio $\left(\frac{P g}{P_{s}}\right)$ has not reached the critical value expressed by Eq. (4), so the mass flow rate is determined primarily by the pressure and temperature of the supply gas according to Eqs. (4) and (7). The mass of the in-cylinder gas will be $3.2 \mathrm{~kg}$ after a fill without cooling and $4.45 \mathrm{~kg}$ after a fill with cooling regardless of the $h A_{c}$ value because the gas temperature eventually equalizes with the temperature of the coolant. The $h A_{c}$ value merely changes the time required for the in-cylinder temperature to reach the coolant temperature, with higher $h A_{c}$ values resulting in shorter times to completely finish the fill. Figure 5 shows the effect of $h A_{c}$ value on the fill time required to reach equilibrium. When the $h A_{c}$ value is $14 \mathrm{~W} / \mathrm{K}$, the time needed to finish the fill will be 30 minutes, which is impractical. When the $h A_{c}$ value is $70 \mathrm{~W} / \mathrm{K}, 10$ minutes is needed, which is reasonable compared to liquid fuels. Around $70 \mathrm{~s}$ is required for the fill when the $h A_{c}=280 \mathrm{~W} / \mathrm{K}$.

\section{NUMERICAL MODEL}

The analytical study suffers from the following assumptions: the cylinder contents are approximated as a single lumped mass, spatial variation in the cylinder conditions are neglected, and the convective heat 
transfer coefficient of the cooling coil is not calculated, but is assumed constant. To quantify the effect of these simplifications on the results of the analytical study and to validate the results against a higher-order method, a CFD model is developed of the fast fill process. ANSYS Fluent ${ }^{\circledR}$, a commercial CFD package employing the finite-volume method to discretise the compressible form of the mass, momentum, and energy conservation equations is used. During the hydrogen filling process studied by Zhao et al. [31] and Itou [32], the influences of gravity and buoyancy forces were found to be negligible if the mass flow rate exceeded $9 \mathrm{~g} / \mathrm{s}$. Since the mass flow rate in this case will be many times greater than $9 \mathrm{~g} / \mathrm{s}$, the flow inside the cylinder is modelled as an axisymmetric flow without buoyancy forces due to gravitational acceleration. The working fluid in the CFD model consists of pure methane with real gas properties determined using the Redlich-Kwong equation of state [33]. The k- $\varepsilon$ turbulence model is applied with modified coefficients $\left(C_{1 \varepsilon}=1.52, C_{2 \varepsilon}=1.92, C_{\mu}=0.09\right)$, as suggested by Ouellette et al. [34].

\subsection{Computational domain and spatial grid}

The computational domain is illustrated in Fig. 6. The gas enters the cylinder through a converging nozzle that has an entrance diameter of $0.01 \mathrm{~m}$ and an exit diameter of $0.005 \mathrm{~m}$. This converging nozzle keeps the incoming gas flow in the subsonic regime to assist in convergence of the numerical method. The geometry is divided into the gas domain and the solid domain consisting of the cylinder wall. Because the thermal resistance of aluminium is much smaller than that of carbon fiber, only the carbon fiber wrap (thermal conductivity, $k=3.7 \mathrm{~W} / \mathrm{m} \cdot \mathrm{K}$; density, $\rho=930 \mathrm{~kg} / \mathrm{m} 3$; specific heat, $C_{p}=1500 \mathrm{~J} / \mathrm{kg} \cdot \mathrm{m}$ ) is considered as cylinder wall for simplicity when building the geometry. The dimensions of the cylinder (length, $L=0.893$ $\mathrm{m}$; outer diameter, $D=0.234 \mathrm{~m}$; wall thickness, $\delta=0.019 \mathrm{~m}$ ) follow the model by Nahavandi [24].

It is assumed that the flow inside the cylinder is axisymmetric with respect to the centerline of the cylinder. Active heat removal is achieved by adding three coils near the front or back of the cylinder, as shown in 
Fig.6 (b) and (c). The active heat removal system is expected to consist of cooling coils installed inside the cylinder and connected to the coolant pump and heat exchanger outside the cylinder. The outside heat exchanger rejects heat to the ambient. For the current study, only the inside cooling coils are considered, and the cooling coils are assumed to maintain uniform and constant surface temperature at $300 \mathrm{~K}$, which is a lower temperature than the surrounding gas, so they transfer heat outside the cylinder. The total heat transfer area is designed as $0.06 \mathrm{~m}^{2}$. Figure 7 shows the unstructured mesh applied in the cases with and without cooling. Mesh refinement is utilized near the inlet region and near the coils where the biggest gas property changes and flow gradients are expected.

\subsection{Boundary and Initial Conditions}

The heat transfer outside the cylinder is considered as free convection. In our model, a convection boundary condition is imposed on the outer wall of the cylinder with a constant heat transfer coefficient of $10 \mathrm{~W} / \mathrm{m}^{2} \cdot \mathrm{K}$, and the ambient air temperature is kept constant at $300 \mathrm{~K}$ throughout the filling process. At the inner wall, a no-slip boundary condition is imposed. The coil surfaces have a constant temperature of $300 \mathrm{~K}$, which equals the coolant temperature imposed in the analytical model. The initial pressure of the gas inside the cylinder is $2 \mathrm{MPa}$. Previous researchers [22,23] have specified pressure and temperature boundary conditions that vary with time to match experimentally measured data, e.g. that of Shipley [13]. However, these conditions do not account for the incoming kinetic energy of the gas. Therefore, in this study a constant total enthalpy boundary condition is applied corresponding to a total temperature of $300 \mathrm{~K}$ and a total pressure that linearly ramps from 4 to $20.6 \mathrm{MPa}$ in the first 3 seconds of the fill and then is maintained at 20.6 MPa for the remainder of the fill. The ramped pressure condition is used to avoid very large pressure ratios at the beginning of the fill, for which convergence of the CFD solver is difficult. Since the ramping time is less than $10 \%$ of the total filling time, it's reasonable to assume that it does not significantly impact 
the pressure and temperature history significantly. Figure 8 compares the numerical results and boundary conditions of this study against the experimentally-matched boundary conditions and results of Navid [24]. The milder pressure boundary condition in that study results in a slower fill compared to the present study.

\subsection{Results and Discussion}

Figures 9-11 present the temporal variation of the average gas pressure, temperature, and mass within the cylinder during the fill, respectively, with and without active heat removal via the cooling coils. As shown in Fig. 9, the average gas pressure increases quickly and almost linearly at the initial stages of the fill. It then gradually slows down due to the decreasing pressure difference. When the active heat removal is added, the average gas pressure increases more slowly due to the fact that the cylinder can hold more mass of natural gas with its relatively lower gas temperature at the same pressure level. The placement of the cooling coils also impacts the fill time; when the cooling coils are located towards the back, the fill time is 5 seconds longer than when the cooling coils are located towards the front. The differences in the cooling coil cases is due to differences in the heat transfer rates the two coil locations can achieve. This is illustrated in Fig. 10 by plotting the temporal variation in the average gas temperature. A significant temperature rise occurs in the first 3 seconds for all simulated cases. In the uncooled case, this is followed by a more gradual monotonic temperature rise for the remainder of the fill as the in-cylinder gas is compressed by the incoming gas. In the cooled cases, however, the initial temperature increase is followed by a decrease in the average gas temperature as the cooling effect overcomes the compression heating and conversion of supply enthalpy to cylinder internal energy. Differences in the cooling rate with coil location are noted; the average gas temperature inside the cylinder with cooling coils in the back is consistently lower than when the cooling 
coils are located in the front. The maximum average gas temperature increase during the fill without cooling is approximately $29 \mathrm{~K}$, compared with $13.3 \mathrm{~K}$ and $10 \mathrm{~K}$ for cooling coils located in the front and back of the cylinder, respectively.

The impact of heat removal on the filled mass of CNG inside the cylinder is shown in Fig. 11, which plots the temporal variation of the mass of in-cylinder gas during the filling process. Removal of the recompression-generated heat allows $7 \%$ more mass of gas can be filled into a cylinder when the cooling coils are located in the back. This number reduces to $4.5 \%$ if the cooling coils are located in the front. These improvements in fill efficiency come at the cost of increased fill times, but the longer fill times are still reasonable compared to liquid fuels. These results provide guidance on the future optimization of the cooling coil placement and heat transfer rates.

The mass increase achievable in the two cooling coil cases is driven by the final average gas temperature, which is a product of the spatiotemporal temperature distribution of the gas within the cylinder. To illustrate the spatiotemporal temperature variation, Fig. 12 shows the spatial temperature distribution inside the cylinder at different time intervals during the fill. The same contour levels can be used for each time instance in Fig. 12(b) and (c) because the range of spatial temperature variation in the cooled cases is comparable to the range in the temporal temperature variation. In contrast, the temporal temperature range for the uncooled case is much larger than the spatial temperature range, and so to better illustrate the spatial temperature variation in Fig. 12(a), different contour levels are used at each time instance.

The discussion of Figure 12 will first describe the thermal behaviour of the uncooled case in Fig. 12(a), and then discuss the impact of the cooling coils. Throughout the fill, a region of cool gas exists near the inlet due to the Joule-Thompson effect that cools the incoming gas as it expands in the cylinder. High temperature 
gas exists immediately above the cooled gas at the front of the cylinder. This high-temperature gas is that which has been compressed by the incoming gas stream and has been heated, and is initially located near the front of the cylinder. As the fill progresses, the temperature steadily increases from the front of the cylinder towards the rear. By the end of the fill, the largest temperature occurs at the back of cylinder, where the compressed gas stagnates and the highest recompression heating takes place.

When cooling coils are located in the front of the cylinder, Fig. 12(c) shows that the spatial temperature distribution is much more uniform. This is because the cooling coils remove heat from the hot gas that accumulates near the front of the cylinder, leading to a relatively more spatially-uniform temperature distribution in the cylinder throughout the fill. In contrast, when the cooling coils are located in the back, Fig. 12(b) shows that heating is much more spatially non-uniform, with high temperatures occurring behind the cooling coils at the back of the cylinder. These high temperatures yield the larger heat transfer rates achieved by the coils in the back, as noted in Fig. 10, and contribute to the better fill efficiency for the case with cooling in the back.

To explain why higher temperatures are observed behind the cooling coils when the coils are located near the rear of the cylinder, the forced convection velocity surrounding the coils needs to be considered. This is illustrated in Fig. 13 by plotting the flow streamlines colored by the velocity magnitude at $t=5 \mathrm{~s}$. The uncooled case in Fig. 13(a) shows that the high-speed fluid occurs near the centerline and a single large recirculation pattern develops in the cylinder. When the cooling coils are located near the front (Fig. 13(b)), the cooling coils have a minimal impact on the flow streamlines. The high-speed flow near the centerline convects around the cooling coils and the large recirculation zone in the cylinder in Fig. 13(a) is largely preserved, although there are two smaller recirculation zones created near the coils. When the cooling coils are located near the back (Fig. 13(c)), the flow pattern is significantly altered. The momentum of the incoming gas has reduced sufficiently and the area of the high-speed region has broadened to the point that the cooling coils present a significant flow obstruction. As a result, the dominant recirculation pattern is 
established only within the space between the inlet and the coils, while downstream of the coils the gas velocity is very low. The nearly stagnant gas surrounding the coils is not mixed with the cooler gas elsewhere in the cylinder, allowing high temperature gas to accumulate in the stagnant zone near the rear of the cylinder, which corresponds the temperature distribution plotted in Fig. 12(b). The resulting large temperature difference between the coil surface and the gas produces the larger heat removal rates noted in Fig. 10 when the coils are located near the back of the cylinder.

A further reason for the decreased fill efficiency in the case with cooling coils located near the front of the cylinder is visible in Figures 12 and 13. From Fig. 13(b), it is apparent that the coil nearest the centreline will have the highest convective heat transfer coefficient because the velocity past the cylinder is the highest. However, Fig. 12(c) shows that the temperature difference between the coil surface and the gas will be small and perhaps even negative during the early stages of the fill. The impact of these flow features on the local heat transfer rate for the three coils (averaged over the coil circumference) is shown in Fig. 14. Initially, the heat transfer rate is positive, i.e. the coils are actually heating the gas, which is of course opposite to their intended purpose. The largest total heating rate occurs at $t=2.5 \mathrm{~s}$, which is approximately when the ramped inlet pressure reaches its maximum value. The coils transition from heating to cooling the gas first for Coil \#3, which is farthest from the inlet, and lastly for Coil \#1, which is nearest to the inlet. The highest total cooling rate occurs at about $t=12 \mathrm{~s}$ for Coil \#3 due to the balance in gas temperature and velocity; with reference to Fig. 12(c) and Fig. 13(b), while Coil \#3 has lower velocities than Coil \#1, it has a larger local temperature difference that yields higher heat transfer rates. In contrast, for the case with cooling coils near the back of the cylinder (not shown), the local heat transfer rates are consistently negative (i.e. cooling) throughout the fill duration.

Finally, to compare the analytical model to the numerical results, Fig. 15 compares the CFD results and the analytical model. To ensure a consistent comparison, the analytical model is corrected by imposing the same ramped inlet pressure as the CFD and the convective heat transfer coefficient of the cooling coils 
calculated from Fig. 14 instead of the constant $h A$ value assumed in Section 2. The comparison in Fig. 15 shows that the corrected analytical model over-predicts the temperature rise and the fill time required compared to the CFD. This over-prediction is likely due to neglecting spatial variations in the analytical model (i.e. the lumped mass assumption), as the CFD results show that spatial variations in the temperature and velocity occur and affect the considered active heat removal strategies for improving the fill efficiency.

\section{CONCLUSIONS}

A combined analytical/computational study of the fast fill of compressed natural gas was performed to investigate the effect of active heat removal on improving the fill efficiency in heavy-duty vehicles. Active heat removal was introduced by adding three coiled tubes inside the cylinder, and the tube surface temperature was assumed to be uniform and constant. The influence of coil placement location was assessed by placing coils either in the front or in the back of the cylinder. The transient and spatial development of temperature, pressure, and dispensed mass of gas were analyzed for the cases with and without heat removal. Both the numerical and analytical results demonstrate that active heat removal lowers the average gas temperature of the dispensed gas so that more mass of natural gas can be dispensed into the cylinder without a significant increase in fill time. Moreover, the location of the cooling coils affects the heat removal due to the relative effects of the gas temperature and velocity distributions inside the cylinder. Placing the coils in the back of the cylinder achieves the largest improvement in fill efficiency, as the high gas temperatures near the rear of the tank yield the largest heat transfer rates for the heat removal system. 


\section{ACKNOWLEDGMENT}

This work is supported by Agility Fuel Systems and Natural Sciences and Engineering Research Council of Canada (NSERC) (CRDPJ485290).

\section{REFERENCES}

[1] Paltsev, S., Jacoby, H. D., Reilly, J. M., Ejaz, Q. J., Morris, J., O’Sullivan, Fin \& Kragha, O. (2011). The future of US natural gas production, use, and trade. Energy Policy, 39(9), 5309-5321. (Journal Article)

[2] Moniz, Ernest J., et al. (2011). "The future of natural gas." Cambridge, MA: Massachusetts Institute of Technology. (Report)

[3] Stephenson, M. H. (2016). Shale gas in North America and Europe. Energy Science \& Engineering, 4(1), 4-13 (Journal Article)

[4] Greene, D. L., \& Plotkin, S. E. (2011). Reducing greenhouse gas emission from US transportation. Arlington: Pew Center on Global Climate Change. (Report)

[5] Yeh, S. (2007). An empirical analysis on the adoption of alternative fuel vehicles: The case of natural gas vehicles. Energy Policy, 35(11), 5865-5875. (Journal Article)

[6] Economides, M. J., Sun, K., \& Subero, G. (2006). Compressed natural gas (CNG): an alternative to liquefied natural gas (LNG). SPE Production \& Operations, 21(02), 318-324. (Journal Article) 
[7] Kountz, K. J. (1994). Modeling the fast fill process in natural gas vehicle storage cylinders (No. CONF940301--42). Institute of Gas Technology, Chicago, IL (United States). (Journal Article)

[8] Kountz, K. J. (1996). Natural Gas Storage Conditions as a Function of Operating Environment. NASA, (19980008507). (Report)

[9] Murray, C. F., Newhouse, N. L., Schimenti, J. D., \& Tiller, D. B. (1992). Development of Composite Pressure Vessels with Non-metallic Liners. In Joint Propulsion Conference and Exhibit. (Proceedings)

[10] Diggins, D. D. (1998). CNG Fuel Cylinder Storage Efficiency and Economy in Fast Fill Operations (No. 981398). SAE Technical Paper. (Technical Paper)

[11] Newhouse, Norman L., and William E. Liss (1999). Fast filling of NGV fuel containers. No. 199901-3739. SAE Technical Paper. (Technical Paper)

[12] Farzaneh-Gord, M., Deymi-Dashtebayaz, M., \& Rahbari, H. R. (2011). Studying effects of storage types on performance of CNG filling stations. Journal of Natural Gas Science and Engineering, 3(1), 334-340. (Journal Article)

[13] Shipley, E. (2002). Study of natural gas vehicles (NGV) during the fast fill process. PhD thesis, West Virginia University. (Thesis)

[14] Thomas, G., Goulding, J., \& Munteam, C. (2002). Measurement, approval and verification of CNG dispensers. NWML KT11 Report. (Report)

[15] Farzaneh-Gord, M. (2008). Compressed natural Gas-Single reservoir filling process. International Gas Engineering and Management, 48(6), 16-18. (Journal Article)

[16] Farzaneh-Gord, M., Eftekhari, H., Hashemi, S., Magrebi, M., \& Dorafshan, M. (2007). The effect of initial conditions on filling process of CNG cylinders. In The Second International Conference on Modeling, Simulation, And Applied optimization, Abu Dhabi, UAE, March (pp. 24-27). (Proceedings)

[17] Farzaneh-Gord, M., Rahbari, H. R., \& Deymi-Dashtebayaz, M. (2014). Effects of natural gas compositions on $\mathrm{CNG}$ fast filling process for buffer storage system. Oil \& Gas Science and Technology-Revue d'IFP Energies Nouvelles, 69(2), 319-330. (Journal Article) 
[18] Kountz, K. J., Kenneth, J., Blazek, C., \& Christopher, F. (1997). NGV fueling station and dispenser control systems. report GRI-97/0398, Gas Research Institute, Chicago, Illinois, November. (Report)

[19] Kountz, Kenneth J., William E. Liss, and Christopher F. Blazek (1998). "Method and apparatus for dispensing compressed natural gas." U.S. Patent No. 5,752,552. (Patent)

[20] Kountz, Kenneth J., William E. Liss, and Christopher F. Blazek (1998). "Automated process and system for dispensing compressed natural gas." U.S. Patent No. 5,810,058. (Patent)

[21] Kountz, K., Blazek, C., \& Liss, W. (1998). A new natural gas dispenser control system. In International Gas Research Conference (Vol. 4, pp. 135-145). Government Institutes Inc. (Proceedings)

[22] Farzaneh-Gord, M., \& Deymi-Dashtebayaz, M. (2013). Optimizing natural gas fueling station reservoirs pressure based on ideal gas model. Polish Journal of Chemical Technology, 15(1), 88-96. (Journal Article)

[23] Dicken, C. J. B., and W. Merida. (2007). "Modeling the transient temperature distribution within a hydrogen cylinder during refueling." Numerical Heat Transfer, Part A: Applications 53.7: 685-708. (Journal Article)

[24] Nahavandi, Navid NoorAliPour, and Mahmood Farzaneh-Gord. (2013). "Numerical simulation of filling process of natural gas onboard vehicle cylinder." Journal of the Brazilian Society of Mechanical Sciences and Engineering 35.3: 247-256. (Journal Article)

[25] Farzaneh-Gord, M., Deymi-Dashtebayaz, M., Rahbari, H. R., \& Niazmand, H. (2012). Effects of storage types and conditions on compressed hydrogen fuelling stations performance. International Journal of Hydrogen Energy, 37(4), 3500-3509. (Journal Article)

[26] Farzaneh-Gord, M., Deymi-DashteBayaz, M., \& Rahbari, H. R. (2013). Effects of gas types and models on optimized gas fuelling station reservoir's pressure. Brazilian Journal of Chemical Engineering, 30(2), 399-411. (Journal Article) 
[27] Deymi-Dashtebayaz, M., Farzaneh-Gord, M., Nooralipoor, N., \& Rastgar, S. (2014). The full simulation of rapid refueling of a natural gas vehicle on-board cylinder. Journal of Natural Gas Science and Engineering, 21, 1099-1106. (Journal Article)

[28] Deymi-Dashtebayaz, M., Farzaneh-Gord, M., Nooralipoor, N., \& Niazmand, H. (2016). The Complete Modelling of The Filling Process of Hydrogen Onboard Vehicle Cylinders. Brazilian Journal of Chemical Engineering, 33(2), 391-399. (Journal Article)

[29] Zhang, G.Y., Brinkerhoff, J.R., Li, R., Forsberg, C. (2016). Increasing fast refill of compressed natural gas by active heat removal. The 2nd Thermal and Fluids Engineering Conference and 4th International Workshop on Heat Transfer, Las Vegas, Nevada, USA, 2017. (Proceedings)

[30] Farzaneh-Gord, M., \& Branch, S. (2009). Real and ideal gas thermodynamic analysis of single reservoir filling process of natural gas vehicle cylinders. Journal of Theoretical and Applied Mechanics, 41(2), 21-36. (Journal Article)

[31] Zhao, L., Liu, Y., Yang, J., Zhao, Y., Zheng, J., Bie, H., \& Liu, X. (2010). Numerical simulation of temperature rise within hydrogen vehicle cylinder during refueling. International Journal of Hydrogen Energy, 35(15), 8092-8100. (Journal Article)

[32] Itou, Y. (2006). Numerical solution to the fast fill process of automotive compressed hydrogen cylinder. Automotive Inst., 28(7), 29-32. (Journal Article)

[33] Li, Q., Zhou, J., Chang, Q., \& Xing, W. (2012). Effects of geometry and inconstant mass flow rate on temperatures within a pressurized hydrogen cylinder during refueling. International Journal of Hydrogen Energy, 37(7), 6043-6052. (Journal Article)

[34] Ouellette, P., and P. G. Hill. (2000). "Turbulent transient gas injections." Journal of Fluids Engineering 122.4: 743-752. (Journal Article) 


\begin{tabular}{|lllll}
\hline Nomenclature & & \\
$\mathrm{A}$ & Area $\left(\mathrm{m}^{2}\right)$ & $\mathrm{T}$ & Temperature $(\mathrm{K})$ \\
$C_{d}$ & Orifice discharge coefficient & $\mathrm{u}$ & Internal energy $(\mathrm{kj} / \mathrm{kg})$ \\
$\mathrm{d}$ & Diameter $(\mathrm{mm})$ & $\mathrm{t}$ & Time $(\mathrm{s})$ \\
$\mathrm{l}$ & Length $(\mathrm{mm})$ & $\mathrm{v}$ & Specific volume $\left(\mathrm{m}^{3} / \mathrm{kg}\right)$ \\
$\mathrm{k}$ & Specific heat ratio & $\mathrm{Subscript}$ & \\
$\mathrm{h}$ & Specific enthalpy $(\mathrm{kj} / \mathrm{kg})$ & $\mathrm{c}$ & Cooling coil \\
& or Heat transfer coefficient $\left(\mathrm{W} / \mathrm{m}^{2} \mathrm{~K}\right)$ & $\mathrm{g}$ & Gas filled \\
$\dot{m}$ & Mass flow rate $(\mathrm{kg} / \mathrm{s})$ & $\mathrm{i}$ & Initial condition \\
$\mathrm{m}$ & Mass $(\mathrm{kg})$ & $\mathrm{s}$ & Supply tank \\
$\mathrm{p}$ & Pressure $(\mathrm{MPa})$ & & \\
\hline
\end{tabular}




\section{Figures}

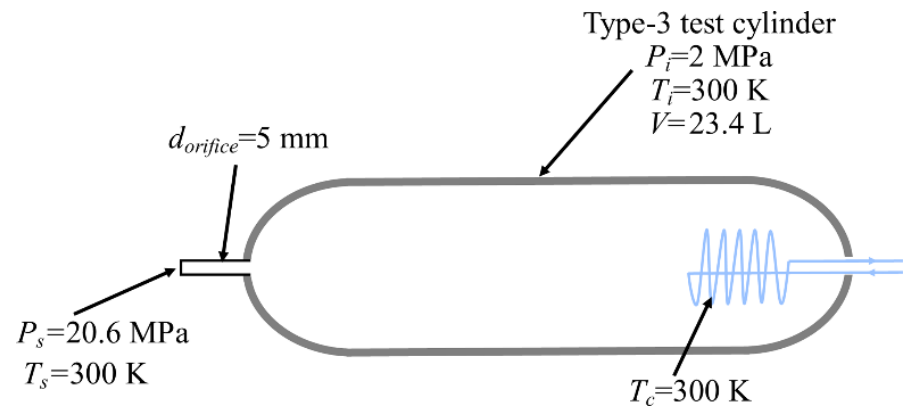

Fig. 1

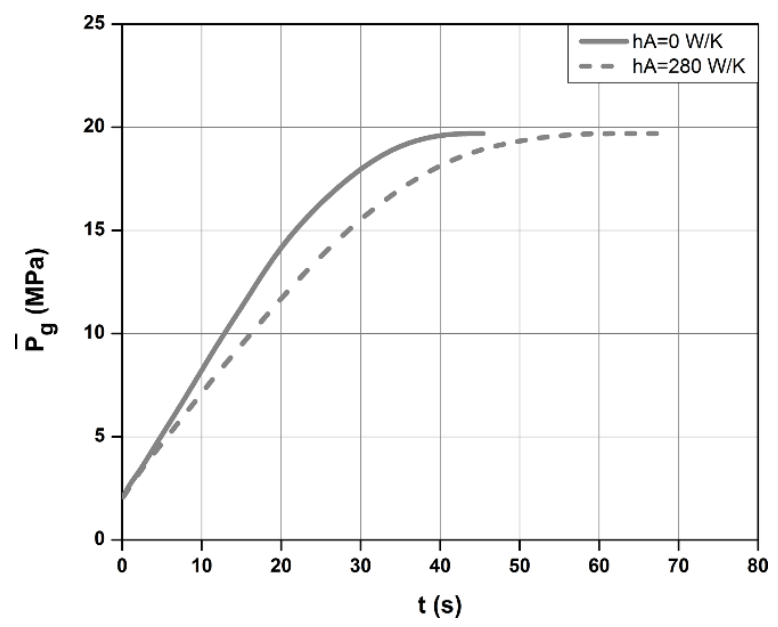

Fig. 2 


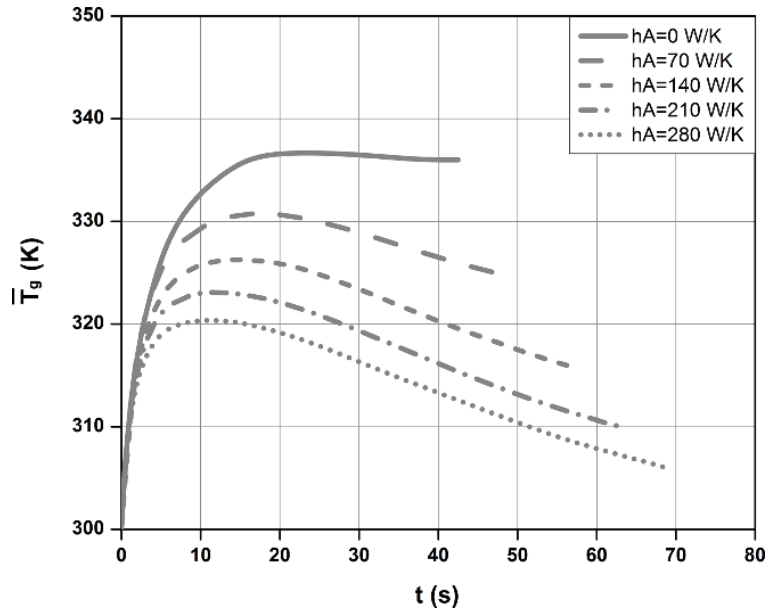

Fig. 3

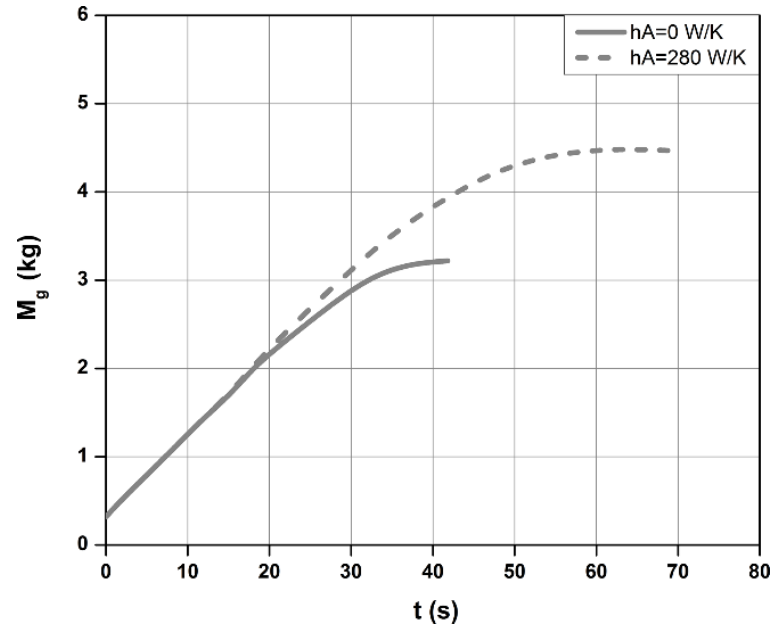

Fig. 4 


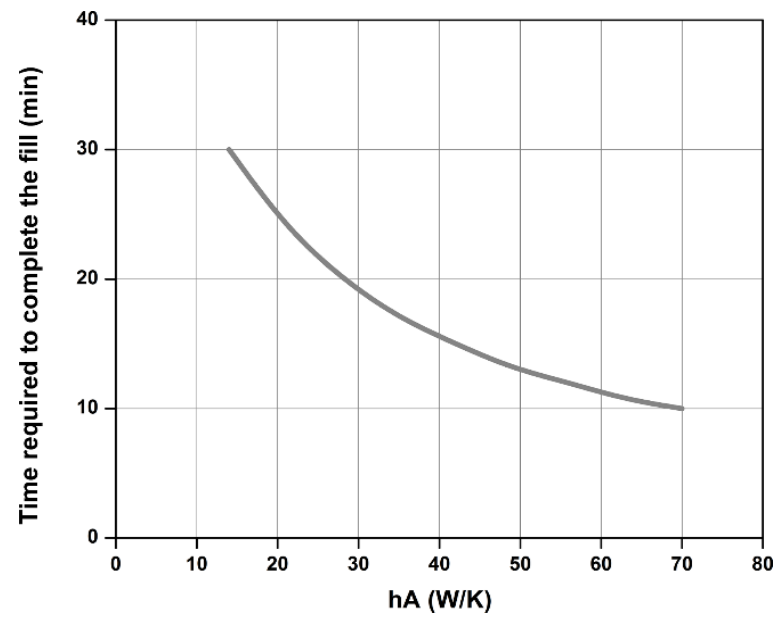

Fig. 5

(a)

(b)

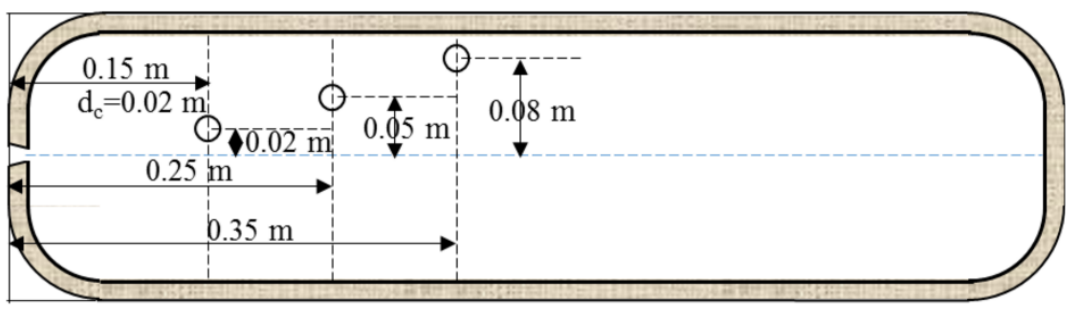

(c)

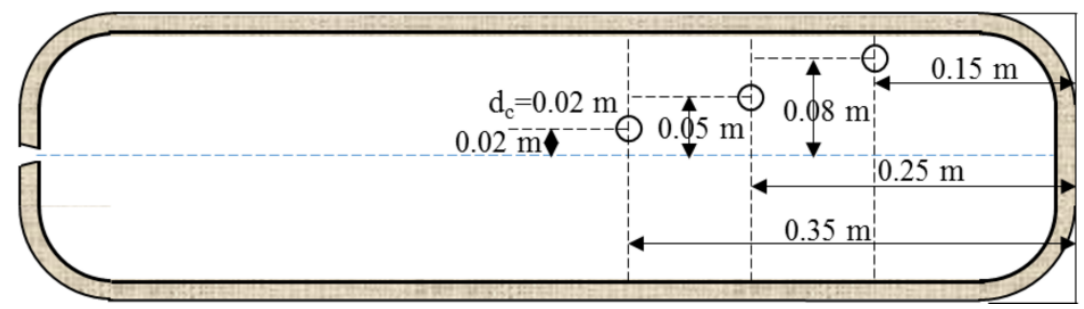

Fig. 6 


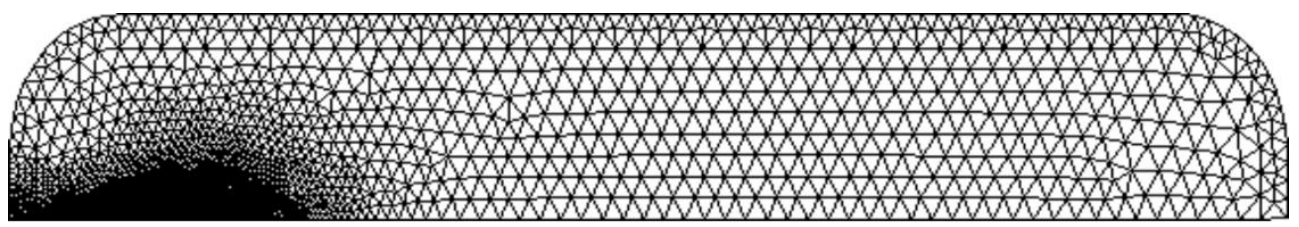

(a)

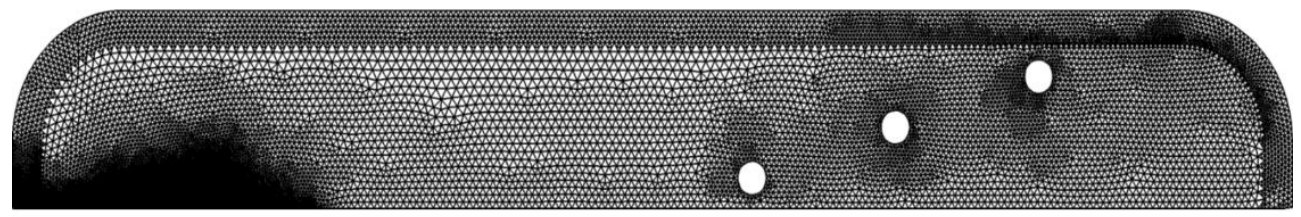

(b)

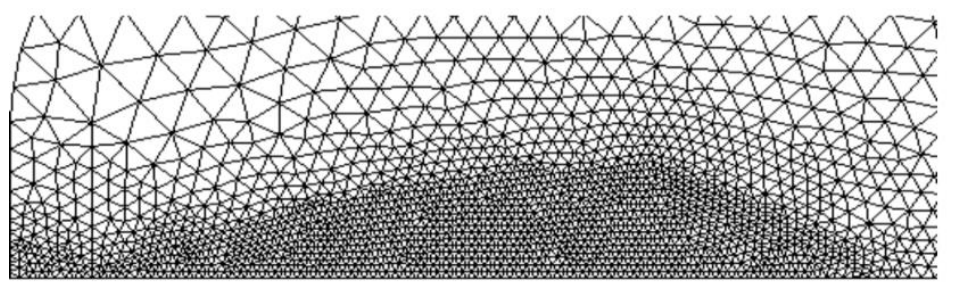

(c)

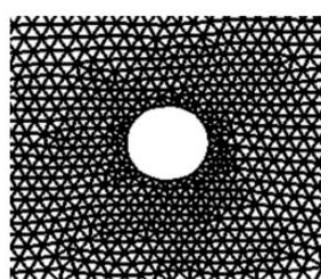

(d)

Fig. 7

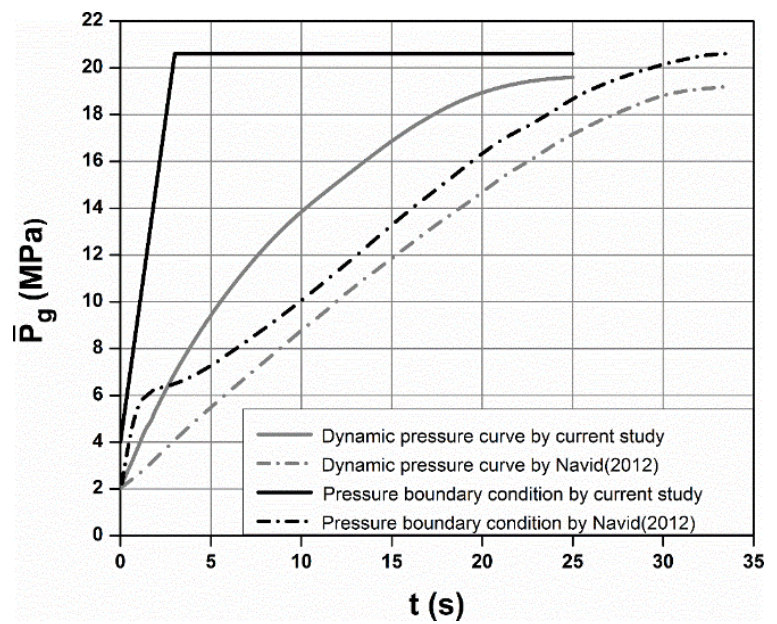

Fig. 8 


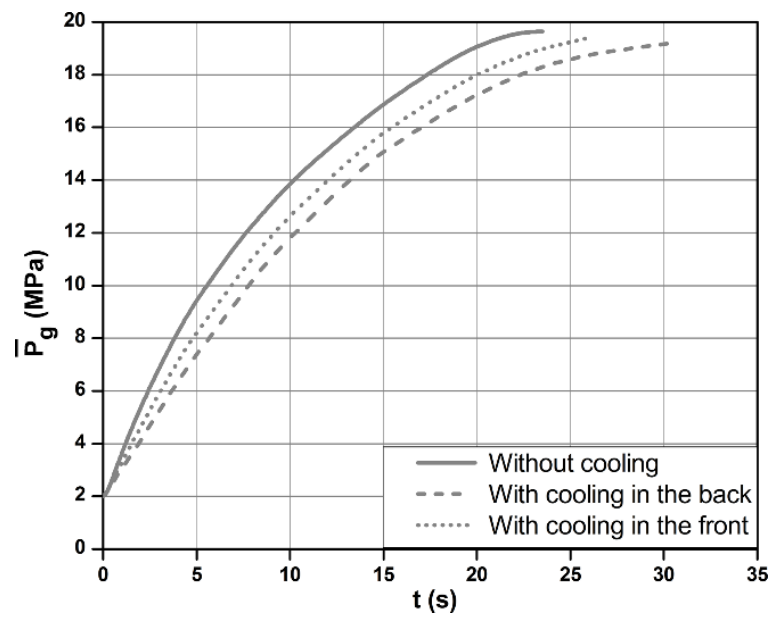

Fig. 9

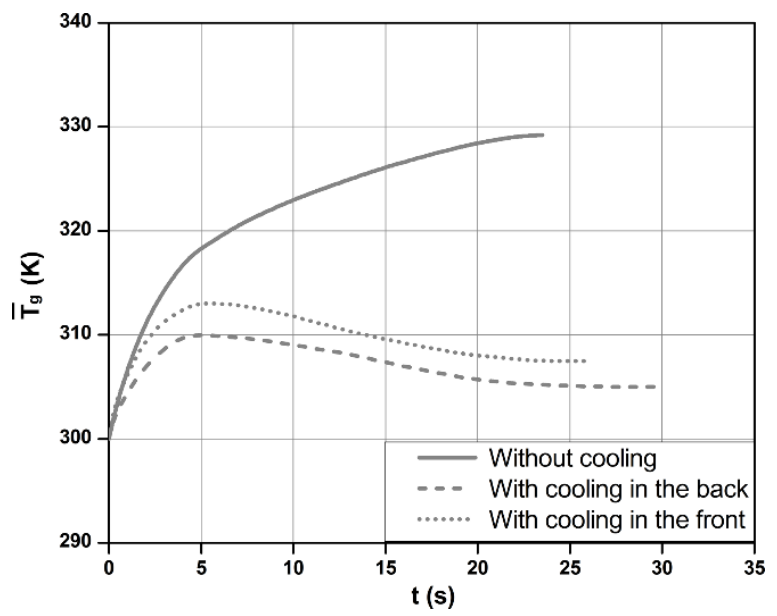

Fig.10 


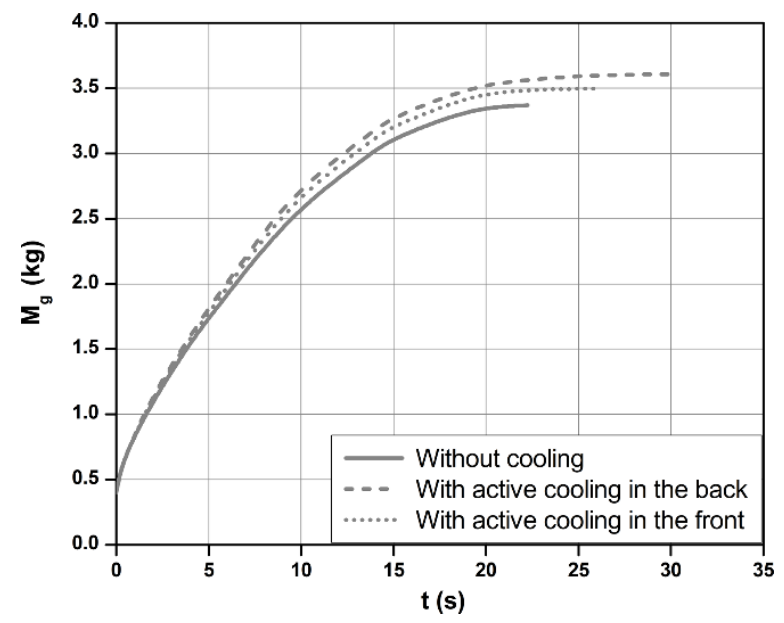

Fig.11

(a) Without cooling

$\mathrm{T}(\mathrm{K})$

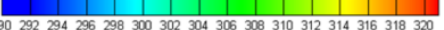

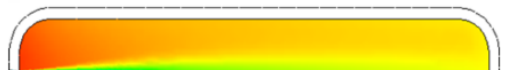

$\mathrm{t}=5 \mathrm{~s}, \mathrm{~T}_{\mathrm{g}}=318.5 \mathrm{~K}$

$\mathrm{T}(\mathrm{K})$
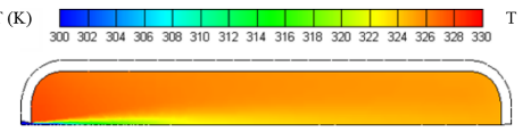

$\mathrm{t}=10 \mathrm{~s}, \mathrm{~T}_{\mathrm{g}}=323 \mathrm{~K}$
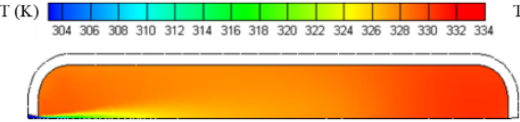

$\mathrm{t}=20 \mathrm{~s}, \mathrm{~T}_{\mathrm{g}}=328.5 \mathrm{~K}$ (b) With cooling in the back

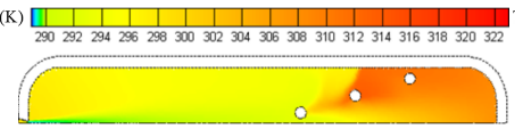

$\mathrm{t}=5 \mathrm{~s}, \mathrm{~T}_{\mathrm{g}}=309.9 \mathrm{~K}$

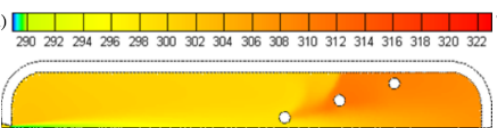

$\mathrm{t}=10 \mathrm{~s}, \mathrm{~T}_{\mathrm{g}}=309 \mathrm{~K}$

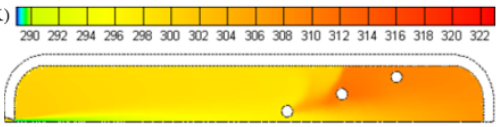

$\mathrm{t}=20 \mathrm{~s}, \mathrm{~T}_{\mathrm{g}}=305.6 \mathrm{~K}$ (c) With cooling in the front

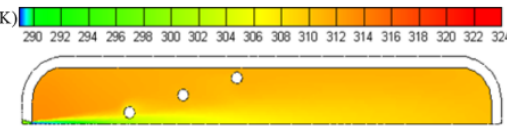

$\mathrm{t}=5 \mathrm{~s}, \mathrm{~T}_{\mathrm{g}}=312.8 \mathrm{~K}$

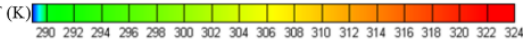

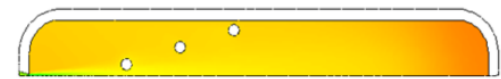

$\mathrm{t}=10 \mathrm{~s}, \mathrm{~T}_{\mathrm{g}}=311.8 \mathrm{~K}$
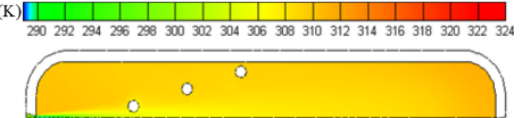

$\mathrm{t}=20 \mathrm{~s}, \mathrm{~T}_{\mathrm{g}}=\mathbf{3 0 7 . 8 \mathrm { K }}$

Fig.12 


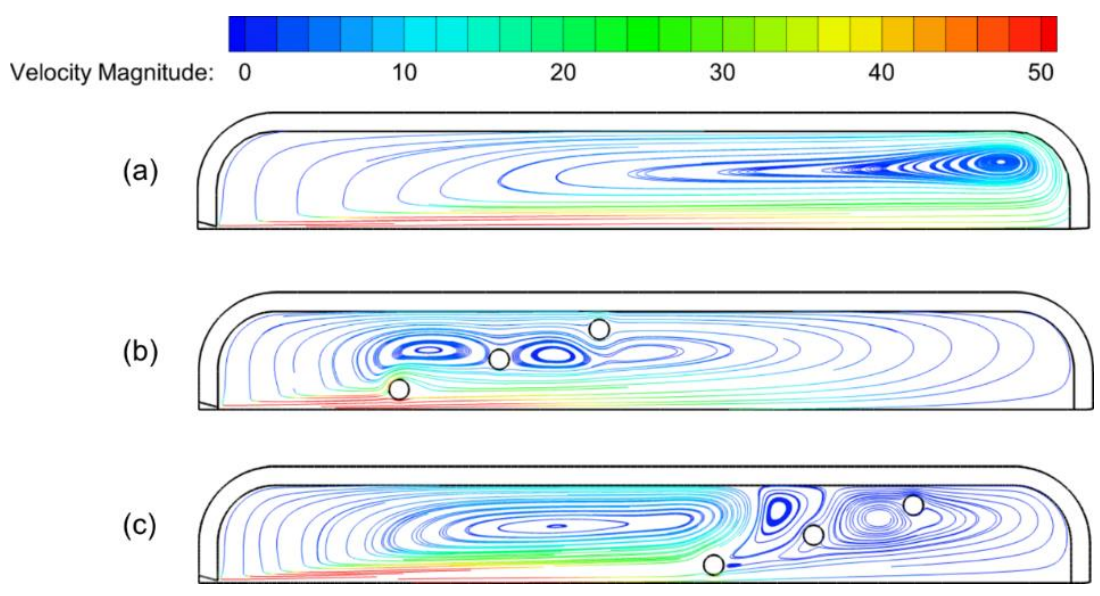

Fig.13

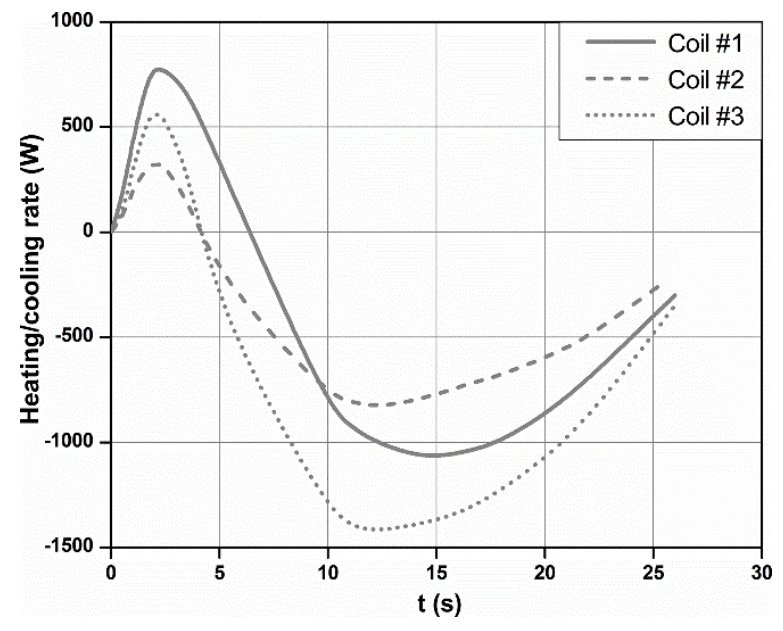

Fig.14 


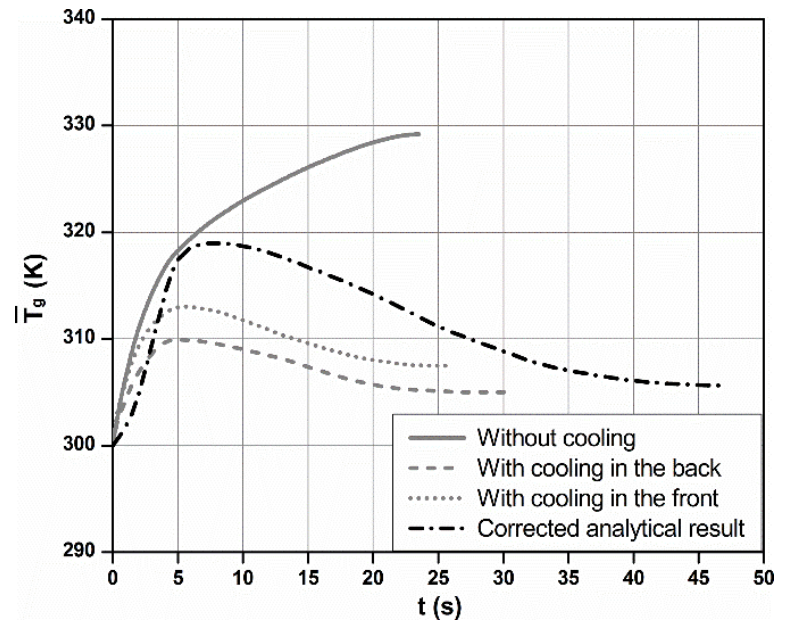

Fig.15 


\section{Figure captions}

Fig. 3 Schematic diagram of the system considered in the analytical model

Fig. 4 Dynamic change in gas average pressure by analytical model

Fig. 3 Dynamic change in gas average temperature by analytical model

Fig. 4 Dynamic change in mass of gas filled by analytical model

Fig. 5 The effect of the $h A_{c}$ value on the fill time

Fig. 6 The computational domain under investigation

Fig. 7 The computational mesh used in this study: (a) the grid for the case without cooling coils; (b) the grid for the case with cooling coils near the back; (c) a zoomed-in view of the refined mesh in inlet region; (d) a zoomed-in view of the refined mesh near the cooling coils.

Fig. 8 Comparison between the pressure boundary conditions and dynamic pressure curves by current study and Navid [24]

Fig. 9 Dynamic change in gas average pressure by numerical model

Fig.10 Dynamic change in gas average temperature by numerical model

Fig.11 Dynamic change in the mass of gas filled by numerical model 
Fig.12 Temperature distribution with and without cooling at time of $5 \mathrm{~s}, 10 \mathrm{~s}$ and $20 \mathrm{~s}$

Fig.13 Flow streamline colored by velocity magnitude at $t=5 \mathrm{~s}$

Fig.14 The heating/cooling rate of the three coils when placed in the front side. Coil \#1 is nearest to the cylinder inlet, and coil \#3 is farthest.

Fig.15 Comparison between the numerical results and the corrected analytical result 